\title{
HUBUNGAN KONDISI FISIK RUMAH DENGAN KEJADIAN PENYAKIT TUBERKULOSIS PARU DI WILAYAH KERJA PUSKESMAS SIGOMPUL KEC. LINTONGNIHUTA KAB. HUMBANG HASUNDUTAN TAHUN 2018
}

Fithri Handayani Lubis ${ }^{1}$, Syska Simamora²,

Institut Kesehatan Deli Husada Delitua

Jl. Besar Deli No. 77 Deli Tua Kab. Deli Serdang - Sumatera Utara 20355

e-mail : fithri.handa@gmail.com

DOI:_ https://doi.org/10.35451/jkg.v1i2.131

\begin{abstract}
Tuberculosis is the old disease that is now one of the biggest in the health sector. The factor of related to the incedence of tuberculosis are ventilation, type of floor, lighting, humidity. The purpose of this study is to find out the relationship between the physical condition of the house and the incidence of pulmonary tuberculosis in the Sigompul Community Health Center Work area Kecamatan Lintongnihuta Kabupaten Humbang Hasundutan. The method research uses Analitycal Observational design with Cross sectional approach. The subject of this study were respondent of Pulmonary Tuberculosis from October to January 2019 with a population of 85 peoples. The sample selection with sistematic random sampling produce of sample 40 peoples. The data collection methods use observation sheets and data analysis using the chi-square test. The results of the study indicate that there is a relationship between ventilatio $(p=0,006)$, type of floor $(p=0,039)$, lighting $(p=0,034)$ and humidity $(p=0,013)$ with the incidence of pulmonary tuberculosis. For the community, it is expected to create a safe home environment for family, celan and healthy lifestyle. For Sigompul Health Center is expected to implement health program that have been implemented by the goverment in recuding the incidence of pulmonary tuberculosis.
\end{abstract}

Keywords : Condition of the house, the incidence of pulmonary tuberculosis

\section{PENDAHULUAN}

Tujuan

pembangunan kesehatan menuju Indonesia Sehat (2015-2025) adalah meningkatkan kesadaran, kemauan dan kemampuan hidup bagi setia orang agar terwujud derajat kesehatan masyarakat yang optimal. Ada beberapa faktor yang mempengaruhi derajat kesehatan masyrakat diantaranya tingkat ekonomi, pendidikan, keadaan lingkungan, kesehatan, dan budaya sosial. 
WHO memperkirakan bahwa jumlah seluruh kasus di dunia akan meningkat dari 7,5 juta pada tahun 1990 menjadi 10,2 juta pada tahun 2000. Jumlah kematian seluruhnya akan meningkat dari 2,5 juta menjadi 3,5 juta. Kenaikan tersebut sebagian disebabkan oleh bertambahnya penduduk di negara negara yang sedang berkembang dan sebagian oleh karena adanya penyebaran virus HIV. Peningkatan ini dapat diberhentikan bila banyak negaranegara menyelenggarakan penanggulangan Tuberkulosis yang efektif (Crofton, dkk, 2018).

Prevalensi penduduk Indonesia yang didiagnosis TB paru oleh tenaga kesehatan tahun 2013 adalah 0.4 persen, tidak berbeda dengan 2007. Lima provinsi dengan TB paru tertinggi adalah Jawa Barat $(0.7 \%)$, Papua $(0.6 \%)$, DKI Jakarta (0.6\%), Gorontalo $(0.5 \%)$, Banten $(0.4 \%)$ Papua Barat (0.4\%) dan Prevalensi Sumatra Utara (0.2\%) (Riskesdas, 2013).

Di Propinsi Sumatera Utara pada tahun 2012 diperkirakan kasus TBC paru sebanyak 22,360 jiwa. Dan pada tahun 2016 diperkirakan kasus TBC sebanyak 17,798 jiwa. Sedangkan pada Kabupaten Humabang Hasundutan pada tahun 2012 diperkirakan kasus TBC sebanyak 309 jiwa dan mengalami penurunan pada tahun 2016 menjadi 184 jiwa kasus penyakit TBC (Profil Dinas Kesehatan Provinsi Sumatera Utara, 2016).

Berdasarakan survei awal yang peneliti lakukan di wilayah kerja Puskesmas Sigompul terdapat 85 penderita TBC atau sekitar $0,25 \%$ dari 33863 jumlah penduduk. Dan Puskesmas Sigompul merupakan salah satu wilayah kerja dengan kasus penyakit TBC paru tertinggi diantaranya memiliki kondisi fisik rumah yang kurang baik.

\section{METODE PENELITIAN}

Penelitian ini merupakan penelitian analitik observasional. Penelitian analitik karena peniliti berupaya mencari hubungan antara variabel yang satu dengan yang lain. Sedangkan disebut dengan observasional karena peniliti hanya melakukan pengamatan atau pengukuran terhadap berbagai jenis variabel subjek penelitian menurut keadaan alamiah, tanpa berupaya melakukan manipulasi atau intervensi (Notoadmodjo, 2012).

Berdasarkan waktu pelaksanaanya penelitian ini bersifat cross sectionalkarena peniliti hanya melakukan observasi atau pengukuran variabel atau mengumpulkan data sekaligus pada suatu saat. Artinya tiap subjek penelitian hanya di observasi sekali saja dan pengukuran dilakukan terhadap sesuatu karakter atau pada saat pemeriksaan (Notoatmodjo, 2012).

Populasi dalam penelitian ini adalah seluruhpasien TBC Paru yang berkunjung ke Puskesmas Sigompul Kecamatan Lintongnihuta Kabupaten Humbang Hasundutan selama 6 bulan terakhir. Sampel yang akan diteliti adalahseluruh warga yang berkunjung ke puskesmas yaitu 85orang.

Pengambilan sampel dilakukan secara acak (probability sampling) agar semua unit dalam populasi memiliki kesempatan yang sama untuk terpilih menjadi sampel pada penelitian ini. Pengambilan sampel dengan menggunakan metode systematic random sampling dengan membuat undian, nomor berapa yang akan menjadi acuan kelipatan yang akan dijadikan sampel.

Besar sampel dapat dihitung dengan rumus Khotari dalam Murti (2006) sebaagai berikut: 


$$
n=\frac{N \cdot Z_{1-\alpha / 2}^{2} P \cdot Q}{d^{2}(N-1)+Z_{1-\alpha / 2}^{2}}
$$

Keterangan:

$\mathrm{n}$ : besar sampel

$\mathrm{N}$ : besar populasi

$\mathrm{P}$ : Perkiraan proporsi (prevalensi)

variabel dependen pada populasi

$(95 \%)$

$\mathrm{Q}: 1-\mathrm{p}$

$Z_{1}-a_{2}$ : statistik $Z(Z=1,96$ untuk $a=$ 0,05 )

d : Data presisi absolut atau largin of

error yang diinginkan diketahui sisi proporsi (5\%)

Berdasarkan rumus di atas, maka besar sampel pada penelitian ini adalah:

$$
\begin{gathered}
=\frac{85(1,96)^{2} 0,95.0,05}{0.05^{2}(85-1)+1,96^{2} 0,95.0,05} \\
=\frac{326,536.0,0475}{0.21+0,18284859} \\
=\frac{15,51046}{0,39284859} \\
=39,48 \approx 40
\end{gathered}
$$

Pengumpulan data dilakukan dengan menggunakan data sekunder, yaitu laporan puskesmas yang berkaitan dengan kondisi fisik rumah di wilayah kerja Puskesmas Sigompul seperti :

1. Data Primer

Data yang dikumpulkan melalui kuesioner meliputi hubungan kondisi fisik rumah dengan kejadian Penyakit Tuberkulosis Paru di Wilayah Kerja Puskesmas Sigompul Kecamatan Lintongnihuta Kabupaten Humbang Hasundutan.

2. Data Sekunder

Data yang diperoleh dari dokumen Puskesmas Sigompul serta literature yang mendukung.

\section{HASIL DAN PEMBAHASAN}

\section{A. Karakteristik Responden}

Secara umum, karakteristik responden pada penelitian berdasarkan data demografi dapat dilihat pada tabel berikut:
Tabel4.1. Distribusi Frekuensi Berdasarkan Karakteristik

\begin{tabular}{|c|c|c|c|}
\hline \multirow[t]{2}{*}{ No. } & \multirow{2}{*}{$\begin{array}{c}\text { Karakteristik } \\
\text { Responden }\end{array}$} & \multicolumn{2}{|c|}{ Jumlah } \\
\hline & & $\mathbf{F}$ & $\%$ \\
\hline \multirow[t]{5}{*}{1.} & Umur & & \\
\hline & $11-20$ tahun & 6 & 15,0 \\
\hline & 21-30 tahun & 10 & 25,0 \\
\hline & $31-40$ tahun & 11 & 27,5 \\
\hline & $>40$ tahun & 13 & 32,5 \\
\hline \multirow[t]{3}{*}{2.} & Jenis Kelamin & & \\
\hline & Laki-laki & 27 & 67,5 \\
\hline & Perempuan & 13 & 32,5 \\
\hline \multirow[t]{4}{*}{3.} & Pekerjaan & & \\
\hline & Petani & 25 & 62,5 \\
\hline & Wiraswasta & 9 & 22,5 \\
\hline & Pelajar & 6 & 15,0 \\
\hline
\end{tabular}
Responden di Wilayah Kerja Puskesmas Sigompul Kecamatan Lintongnihuta Kabupaten Humbang Hasundutan

\section{B. Analisa Univariat}

Tabel 4.2. Distribusi Frekuensi Berdasarkan Kondisi Ventilasi, Jenis Lantai, Pencahayaan, dan

\begin{tabular}{|c|c|c|c|}
\hline \multirow[t]{2}{*}{ No. } & \multirow[t]{2}{*}{ Variabel } & \multicolumn{2}{|c|}{$\begin{array}{c}\text { Kondisi } \\
\text { Fisik } \\
\text { Rumah }\end{array}$} \\
\hline & & $\mathbf{F}$ & $\%$ \\
\hline & Ventilasi & & \\
\hline 1. & $\begin{array}{l}\text { Tidak } \\
\text { memenuhi } \\
\text { syarat }\end{array}$ & 23 & 57,5 \\
\hline \multirow[t]{3}{*}{2.} & $\begin{array}{l}\text { Memenuhi } \\
\text { syarat }\end{array}$ & 17 & 42,5 \\
\hline & Jumlah & 40 & 100 \\
\hline & Jenis Lantai & & \\
\hline 1. & $\begin{array}{l}\text { Tidak } \\
\text { memenuhi } \\
\text { syarat }\end{array}$ & 25 & 62,5 \\
\hline 2. & $\begin{array}{l}\text { Memenuhi } \\
\text { syarat }\end{array}$ & 15 & 37,5 \\
\hline & Jumlah & 40 & 100 \\
\hline
\end{tabular}
Kelembaban Rumah di Wilayah Kerja Puskesmas Sigompul Kecamatan Lintongnihuta Kabupaten Humbang Hasundutan 


\begin{tabular}{llcc}
\hline 1. & $\begin{array}{l}\text { Pencahayaan } \\
\text { Tidak } \\
\text { memenuhi }\end{array}$ & 23 & 57,5 \\
2. & $\begin{array}{l}\text { syarat } \\
\text { Memenuhi } \\
\text { syarat }\end{array}$ & 17 & 42,5 \\
\hline & Jumlah & $\mathbf{4 0}$ & $\mathbf{1 0 0}$ \\
\hline 1. & $\begin{array}{l}\text { Kelembaban } \\
\text { Tidak } \\
\text { memenuhi } \\
\text { syarat }\end{array}$ & 22 & 55,0 \\
Memenuhi & 18 & 45,0 \\
& syarat & $\mathbf{4 0}$ & $\mathbf{1 0 0}$ \\
\hline & Jumlah & Berdasarkan tabel 4.2 & bahwa
\end{tabular}

dapat diketahui bahwa dari 40 rumah yang diobservasi terdapat $23(57,5 \%)$ kondisi ventilasi reponden yang tidak memenuhi syarat dan 17 (42,5\%) yang memiliki kondisi ventilasi responden yang memenuhi syarat. Dari 40 rumah yang diobservasi terdapat $25(62,5 \%)$ kondisi lantai reponden yang tidak memenuhi syarat dan 15 (37,5\%) yang memiliki kondisi lantai responden yang memenuhi syarat. Dari 40 rumah yang diobservasi terdapat $23 \quad(57,5 \%)$ kondisi pencahayaan reponden yang tidak memenuhi syarat dan $17(42,5 \%)$ yang memiliki kondisi pencahayaan responden yang memenuhi syarat.

Dan bahwa dapat diketahui bahwa dari 40 rumah yang diobservasi terdapat 22 $(55,0 \%)$ kondisi kelembaban reponden yang tidak memenuhi syarat dan 18 $(45,0 \%)$ yang memiliki kondisi kelembaban responden yang memenuhi syarat.

\section{Analisa Bivariat}

\section{Tabel 4.3.Hubungan Kondisi Ventilasi dengan Kejadian Tuberkulosis Paru}

di Wilayah Kerja Puskesmas Sigompul Kecamatan Lintongnihuta Kabupaten Humbang Hasundutan tahun 2018

\begin{tabular}{|c|c|c|c|c|c|c|}
\hline \multirow{3}{*}{$\begin{array}{c}\text { Ventila } \\
\text { si }\end{array}$} & \multicolumn{4}{|c|}{$\begin{array}{c}\text { Kejadian TBC } \\
\text { Paru }\end{array}$} & \multirow{2}{*}{\multicolumn{2}{|c|}{ Total }} \\
\hline & \multicolumn{2}{|c|}{ YA } & \multicolumn{2}{|c|}{ TIDAK } & & \\
\hline & $\mathrm{n}$ & $\%$ & $\mathrm{n}$ & $\%$ & $\mathrm{n}$ & $\%$ \\
\hline $\begin{array}{l}\text { TidakMe } \\
\text { menuhi }\end{array}$ & 18 & $\begin{array}{c}45 \\
0\end{array}$ & 5 & $\begin{array}{c}12 \\
5\end{array}$ & $\begin{array}{l}2 \\
3\end{array}$ & $\begin{array}{c}57 \\
5\end{array}$ \\
\hline $\begin{array}{c}\text { Memenu } \\
\text { hi }\end{array}$ & 5 & $\begin{array}{c}12 \\
5\end{array}$ & $\begin{array}{l}1 \\
2\end{array}$ & $\begin{array}{c}30 \\
3\end{array}$ & $\begin{array}{l}1 \\
7\end{array}$ & $\begin{array}{c}42, \\
5\end{array}$ \\
\hline Total & 23 & $\begin{array}{c}57 . \\
5\end{array}$ & $\begin{array}{l}1 \\
7\end{array}$ & $\begin{array}{c}42 . \\
5\end{array}$ & $\begin{array}{l}4 \\
0\end{array}$ & $\begin{array}{c}10 \\
0\end{array}$ \\
\hline $\begin{array}{r}X^{2}= \\
=8,640\end{array}$ & $\%$ & $\begin{array}{l}7,00 \\
(2,0\end{array}$ & & $\begin{array}{l}0,05) \\
5,423\end{array}$ & & OR \\
\hline
\end{tabular}

Dari tabel 4.3 dapat dilihat hasil nilai $p$ - value sebesar 0,006 dengan a 0,05 , sehingga $p$ - value $0,006<0,05$ maka HO ditolak, dapat disimpulkan terdapat hubungan yang signifikan antara kondisi ventilasi dengan kejadian Tuberkulosis Paru di wilayah kerja Puskesmas Sigompul Kecamatan Lintongnihuta Kabupaten Humbang Hasundutan Tahun 2018

Tabel 4.4.Hubungan Kondisi Jenis Lantai dengan Kejadian Tuberkulosis Paru di Wilayah Kerja Puskesmas Sigompul Kecamatan LintongnihutaKabupaten Humbang Hasundutan tahun 2018

\begin{tabular}{|c|c|c|c|}
\hline Jenis & Keja & $\begin{array}{l}\text { TBC } \\
\mathrm{u}\end{array}$ & Total \\
\hline $\mathbf{i}$ & $\mathbf{Y a}$ & Tidak & \\
\hline
\end{tabular}




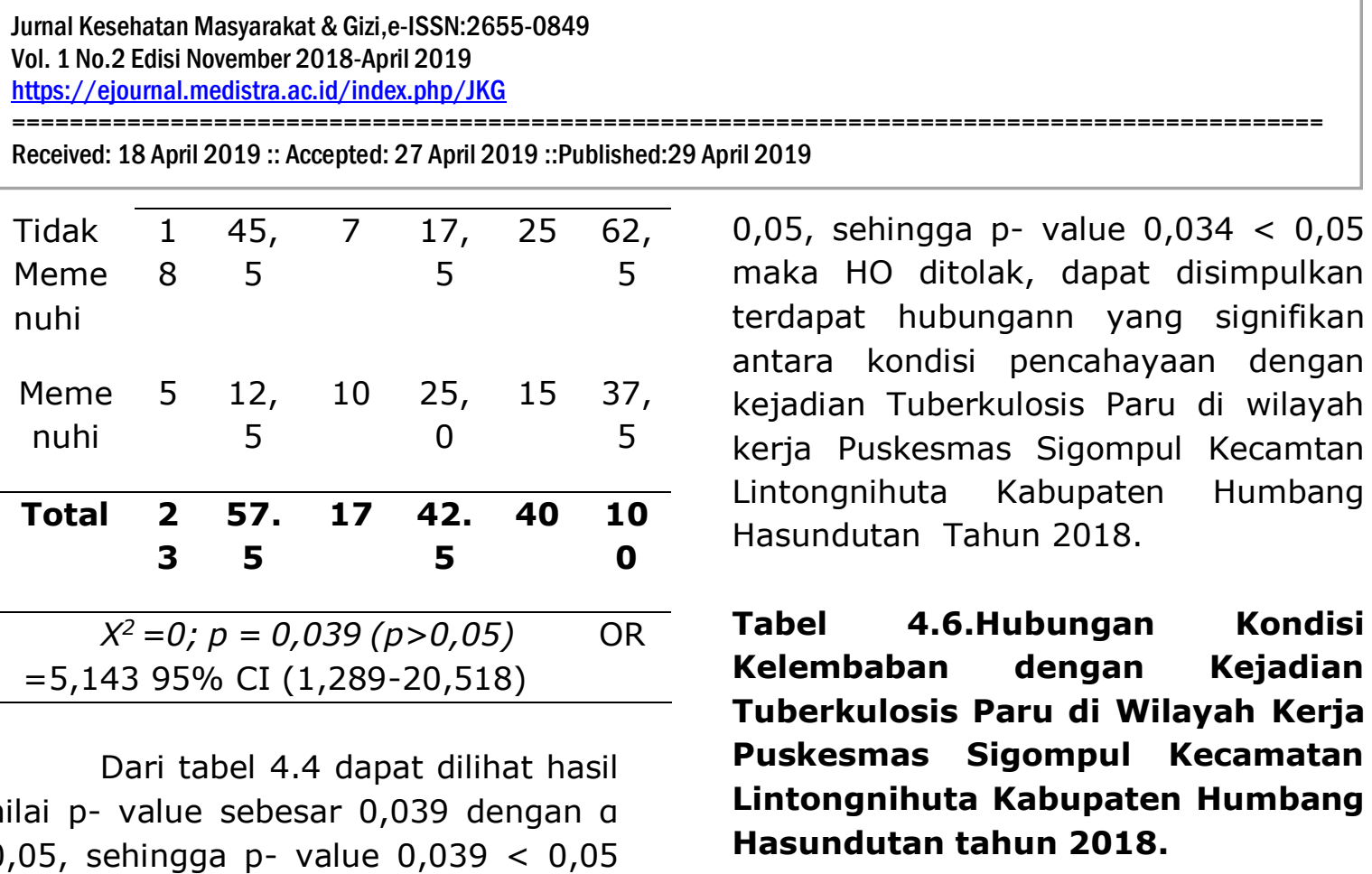

0,05 , sehingga $p$ - value $0,039<0,05$ maka HO ditolak, dapat disimpulkan terdapat hubungann yang signifikan antara kondisi jenis lantai dengan kejadian Tuberkulosis Paru di wilayah kerja Puskesmas Sigompul Kecamatan Lintongnihuta Kabupaten Humbang Hasundutan Tahun 2018.

Tabel 4.5.Hubungan Kondisi Pencahayaan dengan Kejadian Tuberkulosis Paru di Wilayah Kerja Puskesmas Sigompul Kecamatan Lintongnihuta Kabupaten Humbang Hasundutan tahun 2018.

\begin{tabular}{|c|c|c|c|c|c|c|}
\hline \multirow{3}{*}{$\begin{array}{c}\text { Kelemba } \\
\text { ban }\end{array}$} & \multicolumn{4}{|c|}{ Kejadian TBC Paru } & \multirow{2}{*}{\multicolumn{2}{|c|}{ Total }} \\
\hline & \multicolumn{2}{|c|}{$\mathbf{Y a}$} & \multicolumn{2}{|c|}{ Tidak } & & \\
\hline & $\mathrm{n}$ & $\%$ & $\mathrm{n}$ & $\%$ & $\mathrm{n}$ & $\%$ \\
\hline Tidak & 17 & 42, & 5 & 12,5 & 2 & 55, \\
\hline Memenuhi & & 5 & & & 2 & 0 \\
\hline \multirow[t]{2}{*}{ Memenuhi } & 6 & 15 & 12 & 30,0 & 1 & 45 \\
\hline & & 0 & & & 8 & 5 \\
\hline \multirow[t]{2}{*}{ Total } & 2 & 57. & 17 & 42.5 & 4 & 10 \\
\hline & 3 & 5 & & & $\mathbf{0}$ & $\mathbf{0}$ \\
\hline \multicolumn{5}{|c|}{$X^{2}=0 ; p=0,013(p>0,05)$} & \multicolumn{2}{|c|}{ OR } \\
\hline \multicolumn{7}{|c|}{$=6,80095 \%$ CI $(1,680-27,522)$} \\
\hline
\end{tabular}

\begin{tabular}{ccccc}
\hline $\begin{array}{c}\text { Pencahaya } \\
\text { an }\end{array}$ & $\begin{array}{c}\text { Kejadian TBC } \\
\text { Paru }\end{array}$ & Total $\begin{array}{r}X^{2}=0 ; p=0,013(p>0,05) \quad \text { OR } \\
=6,80095 \% \text { CI }(1,680-27,522)\end{array}$ \\
& YA & &
\end{tabular}

YA TIDAK

Dari tabel 4.6 dapat dilihat hasil

\begin{tabular}{ccccccc}
\hline & $\mathbf{n}$ & $\mathbf{\%}$ & $\mathbf{n}$ & $\mathbf{\%}$ & $\mathbf{n}$ & $\mathbf{\%}$ \\
\hline $\begin{array}{c}\text { Tidak } \\
\text { Memenuhi }\end{array}$ & 1 & 42,5 & 6 & 15, & 2 & 57, \\
Memenuhi & 6 & 15,0 & 1 & 27, & 1 & 42, \\
& & & 1 & 5 & 7 & 5 \\
\hline Total & $\mathbf{2}$ & $\mathbf{5 7}$ & $\mathbf{1}$ & $\mathbf{4 2}$ & $\mathbf{4}$ & $\mathbf{1 0}$ \\
& $\mathbf{3}$ & $\mathbf{5}$ & $\mathbf{7}$ & $\mathbf{5}$ & $\mathbf{0}$ & $\mathbf{0}$ \\
\hline$X^{2}=0 ; p=0,034(p>0,05)$ & & OR \\
$=5,19495 \%$ & CI $(1,330-20,284)$ & & \\
\hline
\end{tabular}

nilai $p$ - value sebesar 0,013 dengan a 0,05 , sehingga $p$ - value $0,013<0,05$ $\begin{array}{cccccccc}\text { Tidak } & 1 & 42,5 & 6 & 15, & 2 & 57, & \text { maka HO ditolak, dapat disimpulkan } \\ \text { Memenuhi } & 7 & & & 0 & 3 & 5 & \begin{array}{l}\text { terdapat } \\ \text { antara kondisi kelembaban dengan }\end{array} \\ \text { Memenuhi } & 6 & 15,0 & 1 & 27, & 1 & 42, \begin{array}{l}\text { kejadian Tuberkulosis Paru di wilayah } \\ \text { kemann }\end{array} \\ & & & 1 & 5 & 7 & 5 & \text { kerja Puskesmas Sigompul Kecamtan }\end{array}$ - Lintongnihuta Kabupaten Humbang Hasundutan Tahun 2018.

\section{KESIMPULAN}

Berdasarkan hasil penelitian yang telah dilakukan pada masyarakat

Dari tabel 4.5 dapat dilihat hasil nilai $p$ - value sebesar 0,034 dengan a di Wilayah Kerja Puskesmas Sigompul yaitu hubungan kondisi fisik rumah 
dengan kejadian Tuberkulosis Paru diperoleh kesimpulan bahwa:

1. Berdasarkan uji statistik menunjukkan bahwa terdapat hubungan yang signifikan ( $p=0,006$ ; $0,006<0,05)$ antara Ventilasi dengan kejadian Tuberkulosis Paru di Wilayah Kerja Puskesmas Sigompul Kecamataan Lintongnihuta Kabupaten Humbang Hasundutan Tahun 2018.

2. Berdasarkan uji statistik menunjukkan bahwa terdapat hubungan yang signifikan ( $p=0,039$ ; $0,039<0,05$ ) antara Jenis Lantai dengan kejadian Tuberkulosis Paru di Wilayah Kerja Puskesmas Sigompul Kecamataan Lintongnihuta Kabupaten Humbang Hasundutan Tahun 2018.

3. Berdasarkan uji statistik menunjukkan bahwa terdapat hubungan yang signifika ( $p=0,034$; $0,034<0,05)$ antara Pencahayaan dengan kejadian Tuberkulosis Paru di Wilayah Kerja Puskesmas Sigompul Kecamataan Lintongnihuta Kabupaten Humbang Hasundutan Tahun 20

4. Berdasarkan uji statistik menunjukkan bahwa terdapat hubungan yang signifikan ( $p=0,013$ ; 0,013<0,05) antara Kelembaban dengan kejadian Tuberkulosis Paru di Wilayah Kerja Puskesmas Sigompul Kecamataan Lintongnihuta Kabupaten Humbang Hasundutan Tahun 2018

\section{SARAN}

1. Bagi Masyarakat

Saran untuk masyarakat terutama orang tua untuk menciptakan lingkungan rumah yang aman bagi anggota keluarga serta berperilaku hidup bersih dan sehat.

2. Bagi Wilayah Kerja Puskesmas Setempat

Diharapkan bagi Puskesmas setempat melaksanakan kebijakan program kesehatan yang telah ditetapkan oleh pemerintah dalam mengurangi angka kejadian Tuberkulosis Paru.

3. Bagi Peneliti Lanjut

Diharapkan bagi peneliti selanjutnya untuk melengkapi hasil penelitian yang telah ada dan mengikuti perkembangan ilmu pengetahuan.

\section{DAFTAR PUSTAKA}

Ahmad, Hudoyo, 2014. Tuberkulosis Mudah Diobati Jakarta : Fakultas Kedokteran Iniversitas Indonesia

Erwin, Ulinnuha Fahreza, dkk. 2012, Hubungan Antara Kualitas Fisik Rumah dan Kejadian TB Paru Dengan Basil Tahan Asam Positif di Balai Kesehatan Paru Masyrakat. Semarang : Fakultas Kedokteraan Universitas Muhammadiyah Semarang (Jurnal).

Crofton, Jhon,dkk. 2018. Tuberkulosis

Klinis. Jakarta : Widya Medika

Depkes RI. 2013, Laporan Hasil Riset Kesehatan Dasar Indonesia Tahun 2013, Badan Penelitian dan Pengembangan Kesehatan,Jakarta.

Ferdy, Ricardo Sinaga, dkk. 2016.

Hubungan Kondisi Ventilasi Rumah Dengan Kejadian TB Paru Di Wilayah Puskesmas . Jakarta Direktorat Jendral Bina Upaya Kesehatan (Jurnal).

Dinas Kesehatan Propinsi Sumatera Utara. 2012, Profil Kesehatan PropinsiSumatera Utara. 
Dinas Kesehatan Propinsi Sumatera Utara. 2017, Profil Kesehatan PropinsiSumatera Utara.

Keputuan Menteri Kesehatan RI Nomor 829 Menkes SK/VII/1999 Tentang Persyaratan Perumahan Sehat. Jakarta.

Masriadi, H. 2017, Epidemiologi Penyakit Menular. Depok : PT Rahagrafindo Persada

$\mathrm{Ni}$ MadeMertaniasuh,dkk. 2013, Tuberkulosis Diagnostik Mikrobiologis. Surabaya : Airlangga University Press.

Notoatmodjo, Soekidjo. 2012. Kesehatan Masyarakat IImu, Ilmu dan Seni. Jakarta : PT Rineka Cipta

Notoatmodjo, Soekidjo. 2017. Kesehatan Masyarakat IImu, IImu dan Seni. Jakarta : PT Rineka Cipta.

Peraturan Menteri Kesehatan Rebuplik Indonesia NO. 1077/MENKES/PER/2011.

Tentang Pedoman Penyehatan Udara Dalam Ruang Rumah. Jakarta: http//wwwgoogle.com/depkes.g o.id.PMKNNo. client=1077=new. pdf.

Tjandra, Yoga Aditama. 2013. Tuberkulosis, Rokok, Dan Perempuan. Jakarta: Fakultas Kedokteran Universitas Indoensia. 